\title{
Precision of a Splitting Device for Water Samples
}

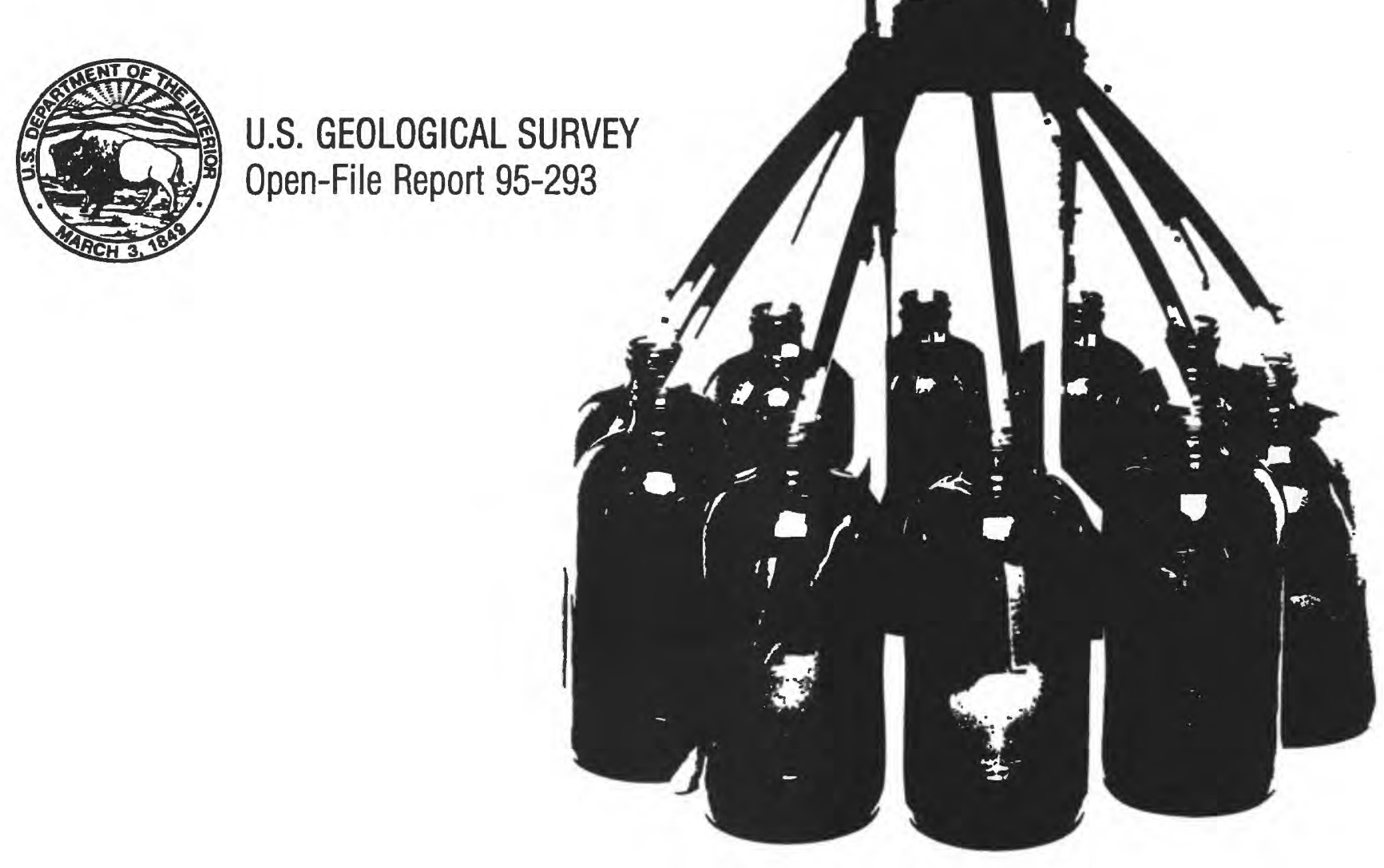




\section{Precision of a Splitting \\ Device for Water Samples}

By Paul D. Capel, Fernando C. Nacionales, and Steven J. Larson

U.S. GEOLOGICAL SURVEY

Open-File Report 95-293

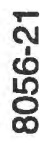




\section{U.S. DEPARTMENT OF THE INTERIOR BRUCE BABBITT, Secretary}

\section{U.S. GEOLOGICAL SURVEY \\ Gordon P. Eaton, Director}

Any use of trade, product, or firm names in this publication is for descriptive purposes only and does not imply endorsement by the U.S. Government.

For sale by the

U.S. Geological Survey

Earth Science Information Center

Open-File Reports Section

Box 25286, MS 517

Denver Federal Center

Denver, CO 80225

For additional information write to:

District Chief

U.S. Geological Survey

Federal Building, Room W-2233

2800 Cottage Way

Sacramento, CA 95825 


\section{CONTENTS}

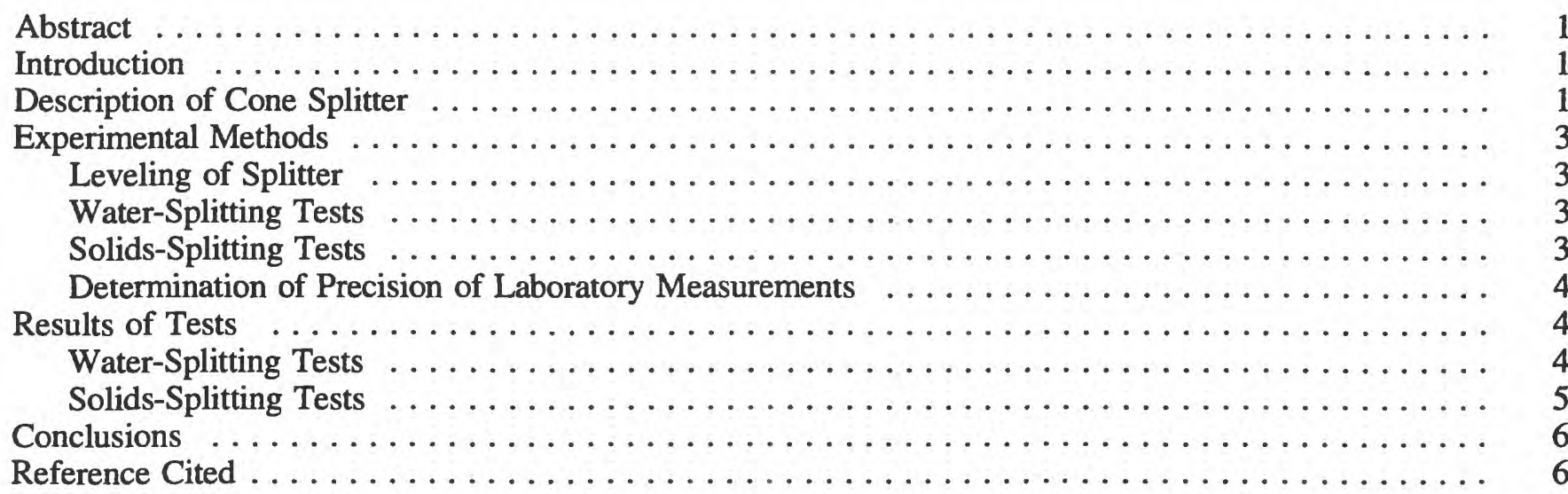

\section{FIGURES}

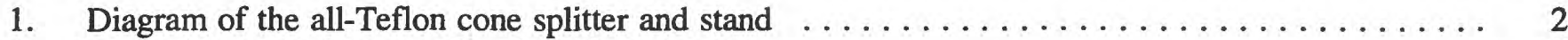

2. Example results from a split of solids and water . .................... 5

3. Effect of solids diameter and concentration on the percentage of relative standard deviation of the solids splitting

\section{TABLES}

1. Particle-size classes and diameter ranges of the solids used in cone-splitter evaluation . . . . . . . 3

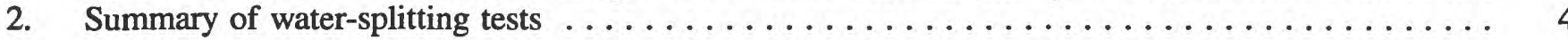


CONVERSION FACTORS AND ABBREVIATIONS

Conversion Factors

\begin{tabular}{rll}
\hline Multiply & By & To obtain \\
\hline liter (L) & 0.2642 & gallon \\
millimeter (mm) & 0.03937 & inch \\
\hline
\end{tabular}

Temperature is given in degrees Celsius $\left({ }^{\circ} \mathrm{C}\right)$, which can be converted to degrees Fahrenheit $\left({ }^{\circ} \mathrm{F}\right)$ by the following equation:

$$
{ }^{\circ} \mathrm{F}=1.8\left({ }^{\circ} \mathrm{C}\right)+32
$$

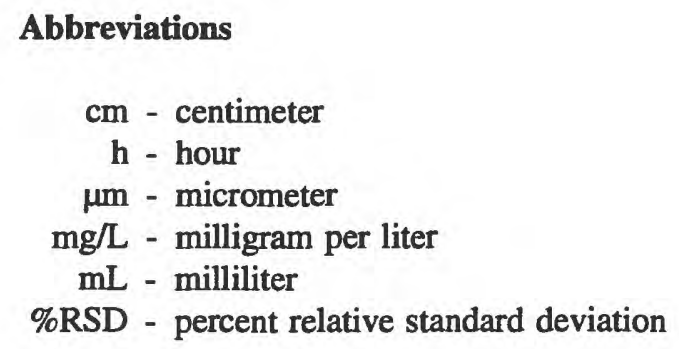




\title{
Precision of a Splitting Device for Water Samples
}

\author{
By Paul D. Capel, Fernando C. Nacionales, and Steven J. Larson
}

\begin{abstract}
Two identical cone splitters, devices designed to split water and its suspended solids into equal aliquots for semi-volatile organic chemical and trace-element analyses, were evaluated for their precision. The water-splitting evaluations consisted of experiments to test the effect of water volume, the effect of combining outlet ports, and the effect of different techniques of water introduction. The solids-splitting evaluations consisted of experiments to test the effect of particle size (nine different particle diameters ranging from very coarse sand to clay) and suspended-solids concentration. In general, water was equally split with a precision of less than 5 percent relative standard deviation. The accuracy of splitting the solids was a function of particle size. Clay, silt, and fine and medium sand were split with a precision relative standard deviation of less than 7 percent, and coarse sand was split with a relative standard deviation between 12 and 45 percent.
\end{abstract}

\section{INTRODUCTION}

The cone splitter is a device developed to split small- to very large-volume water samples for suspended solids and other water-quality constituents into equal concentration aliquots. Since its development, the cone splitter commonly has been used in water-sampling techniques. The original plastic design splits water samples as small as $250 \mathrm{~mL}$ into 10 subsamples with an accuracy of \pm 3 percent (R.S. Pickering, U.S. Geological Survey, written com- mun., 1980). In recent years, concerns of contamination and sorption of the plastic cone splitters have led to the development of an all-Teflon cone splitter for water samples that are to be analyzed for semivolatile organic chemicals and trace elements. The design of the all-Teflon cone splitter is similar to the design of the plastic devices. In this study, the all-Teflon cone splitter was systematically evaluated for its precision in equally splitting water and suspended solids of various particle-size ranges.

Experiments with the cone splitter, which were conducted as part of a comprehensive investigation of pesticides in surface and ground water of the United States, are described in this report. The investigation is part of the National Water Quality Assessment Program of the U.S. Geological Survey.

\section{DESCRIPTION OF CONE SPLITTER}

The all-Teflon cone splitter (Dekaport Splitter, GeoTech Environmental Equipment, Denver, Colorado) consists of a cylindrical reservoir, funnel, stand pipe, and cone splitter housing with 10 outlet ports (fig. 1). The cone splitter housing is precisely machined from one block of Teflon with holes drilled at a 45-degree angle from the vertical and spaced at 36-degree intervals around the circumference. The drilled holes converge at the center of the housing, creating a single point for splitting. The resultant configuration in the splitting chamber is a notched cone with 10 equally spaced outlet ports (6-mm inside diameter opening) about its base. Walls and surfaces inside the splitting chamber are smooth so that water or solids will not be retained and interfere with the splitting process. In the all-Teflon cone splitter, the reservoir is not screened as it is in the plastic cone splitter. 


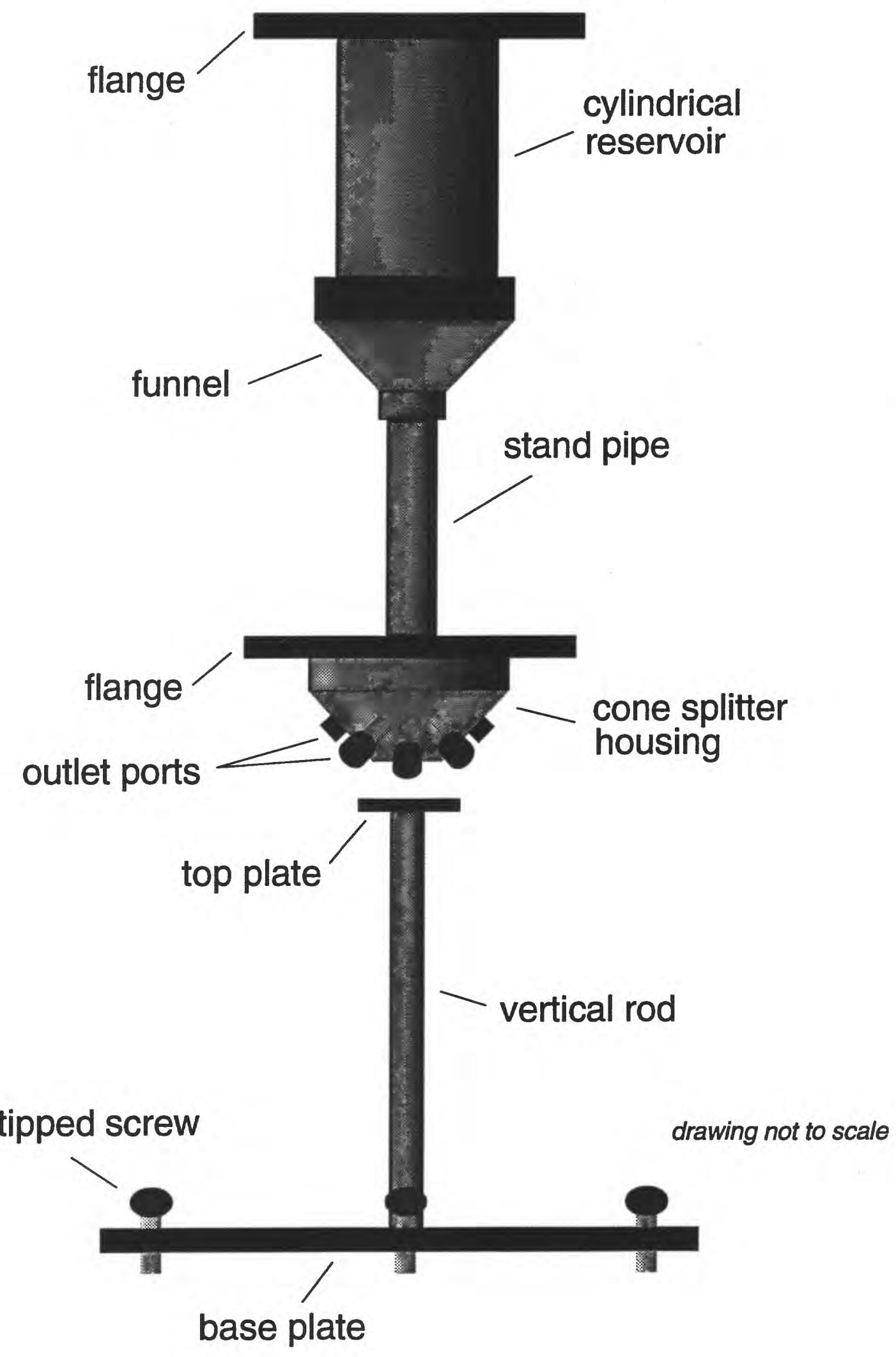

Figure 1. The all-Teflon cone splitter and stand. 


\section{EXPERIMENTAL METHODS}

\section{Leveling of Splitter}

Equal splitting of water and solids is based on the premise that whatever falls on the center point of the cone has an equal chance of being diverted to any of the 10 outlet ports. If the cone splitter is not leveled, then the chance of water or solids exiting from the downside ports will be greater than from the upside ports, and the cone will not work effectively. The manufacturer of the all-Teflon cone splitter supplied three support legs that were to be screwed into the bottom of the cone housing. During testing, the support legs were determined to be awkward to use and unstable, so that it was extremely difficult to level the splitter properly. Because of this, a new support stand was designed (fig. 1).

The cone splitter was leveled by placing it on the stand with a fine-bubble level resting on the cone housing flange. The screws in the base plate were adjusted until the bubble stayed at the center of the bubble level when the level was turned in various directions.

\section{Water-Splitting Tests}

Two identical all-Teflon cones splitters were tested, denoted as " $\mathrm{A}$ " and "B" throughout this report. Deionized water volumes of $0.6,0.8,1,4$, 8 , and $9 \mathrm{~L}$ were continuously introduced into the cone splitters, split 10 ways, and collected in preweighed, clean, dry 1-L glass bottles. Each bottle was weighed on an analytical balance to determine water mass and volume. Replicate tests were conducted for each of the volumes listed above.

When using the cone splitter in the field, uneven volumes of replicate water samples commonly are desirable for different laboratory analyses. One way to collect uneven volumes is to combine the outlet ports of the cone splitter. In combining outlet ports, theoretically there should be no additional head loss, and the integrity of the splitting should be maintained, as long as the tubing used to combine the outlet ports is of a larger diameter than the tubing coming from the cone housing. To test the effect of combining outlet ports, the ports were combined in various ways with large diameter (9-mm outside diameter) Tygon tubing. The ports were configured into six single outlets and two double outlet combinations (eight-way split) for four tests. The ports were configured into five sets of double outlets (five-way split) for five tests. The ports were configured into two sets of three outlets and one set of four outlets (three-way split) for three tests. In all these tests, $1 \mathrm{~L}$ of deionized water was used.

In another series of tests, duplicate 1-L and 9-L volumes of water were poured into the cone splitter from one location in $50-\mathrm{mL}$ aliquots to evaluate the effect of interrupted water introduction into the splitter. In separate tests, the location of the water pouring around the circumference of the reservoir was changed, but the interrupted pouring technique was held constant.

\section{Solids-Splitting Tests}

Aquifer solids from Bemidji, Minnesota, were sequentially wet sieved through a series of brass sieves and nylon filters to sort the sediment into nine different particle-size classes (table 1). Brass sieves were used to isolate six size fractions ranging in diameter from $2,000 \mu \mathrm{m}$ to $38 \mu \mathrm{m}$. Nylon filters were used to isolate three size fractions ranging in diameter from $38 \mu \mathrm{m}$ to $1 \mu \mathrm{m}$. The solids were dried in an oven at $105^{\circ} \mathrm{C}$ for at least $24 \mathrm{~h}$. A predetermined mass was weighed on an analytical balance and mixed into a known volume of deionized water to prepare the desired suspended-solids concentration.

Table 1. Particle-size classes and diameter ranges of the solids used in cone-splitter evaluation

[Range is shown in micrometers]

\begin{tabular}{|c|c|c|}
\hline Size class & $\begin{array}{l}\text { Diameter } \\
\text { range }\end{array}$ & $\begin{array}{l}\text { Log diameter } \\
\text { range }\end{array}$ \\
\hline \multicolumn{3}{|l|}{ Sand } \\
\hline Very coarse $\ldots .$. & $2,000-1,000$ & $3.30-3.00$ \\
\hline Coarse . . . . . . . . & $1,000-500$ & $3.00-2.70$ \\
\hline Medium $\ldots \ldots \ldots$ & $500-250$ & $2.70-2.40$ \\
\hline Fine $\ldots \ldots \ldots \ldots$ & $250-125$ & $2.40-2.10$ \\
\hline Very fine $\ldots . .$. & $125-62$ & $2.10-1.79$ \\
\hline \multicolumn{3}{|l|}{ Silt } \\
\hline Coarse ......... & $62-38$ & $1.79-1.58$ \\
\hline Coarse to medium .. & $38-21$ & $1.58-1.32$ \\
\hline Medium to fine .... & $21-10$ & $1.32-1.00$ \\
\hline \multicolumn{3}{|l|}{ Silt and clay } \\
\hline Very fine & $10-1$ & $1.00-0.00$ \\
\hline
\end{tabular}


For each of the nine different particle-size ranges, test sample suspensions were made with particle concentrations of 50 and $200 \mathrm{mg} / \mathrm{L}$. Each suspension was split into 10 aliquots using the leveled cone splitter. The water and sediment mixture was collected in 10 preweighed, 1-L glass bottles and then filtered through a dried and preweighed paper filter (VWR, Grade 415, diameter: $7.5 \mathrm{~cm}$ ) in a Buchner funnel for particle-size diameters as small as $38 \mu \mathrm{m}$ or through a dried and preweighed nylon membrane filter (Lida, filter diameter: $47 \mathrm{~mm}$, pore opening $0.45 \mu \mathrm{m}$ ) for particle-size diameters from 1 to $38 \mu \mathrm{m}$. The total volume of water passed through the filter was collected and weighed to determine its mass. The filter was removed with forceps and transferred to an aluminum pan for drying. The filter was dried at $105^{\circ} \mathrm{C}$ for at least $24 \mathrm{~h}$ and then reweighed on an analytical balance. The difference in mass was attributed to the solids present on the filter. The suspended-solids concentration of the water exiting each of the 10 outlet ports was calculated from the mass of solids retained by the filter and the volume of water.

\section{Determination of Precision of Laboratory Measurements}

The precision of the various laboratory measurements (weighing a mass of solids, determining a water volume, and calculating a solids concentration) was determined. The 10 replicates of the 10 samples (100 measurements) of solids mass, water volume, and solids concentration were used to determine the precision. The average percent relative standard deviation (\%RSD) of the water volume measurement was 0.012 percent; the average \%RSD of the mass of solids measurement was 0.384 percent; and the average \%RSD of the suspended-solids concentration measurement was 0.385 percent.

\section{RESULTS OF TESTS}

\section{Water-Splitting Tests}

The results of the water-splitting tests are summarized in table 2. The \%RSD, an indication of the precision of the cone splitter, was calculated for each test. Two identical all-Teflon cone splitters of the same model ("A" and "B" in table 2) were evaluated using a 0.6-L test volume, providing a comparison of manufacturing consistency. The pre-
Table 2. Summary of water-splitting tests

[\%RSD, Percentage of relative standard deviation]

\begin{tabular}{|c|c|c|c|}
\hline $\begin{array}{l}\text { Description } \\
\text { of test }\end{array}$ & $\begin{array}{l}\text { Cone } \\
\text { splitter }\end{array}$ & $\begin{array}{l}\text { Number } \\
\text { of tests }\end{array}$ & $\begin{array}{c}\text { Average \%RSD } \\
\text { of volumes } \\
\text { of splits }\end{array}$ \\
\hline \multicolumn{4}{|c|}{ Effect of water volume } \\
\hline $9 \mathrm{~L}$ & A & 2 & 3.7 \\
\hline $8 \mathrm{~L}$ & A & 3 & 4.3 \\
\hline $4 \mathrm{~L}$ & A & 5 & 3.4 \\
\hline $1 \mathrm{~L}$ & A & 3 & 3.2 \\
\hline $0.8 \mathrm{~L}$ & A & 3 & 3.8 \\
\hline $0.6 \mathrm{~L}$ & A & 3 & 4.9 \\
\hline $0.6 \mathrm{~L}$ & B & 5 & 4.3 \\
\hline \multicolumn{4}{|c|}{ Effect of combining outlet ports } \\
\hline Eight-way split & A & 4 & 2.5 \\
\hline Five-way split & A & 4 & 3.5 \\
\hline Three-way split & A & 3 & 2.0 \\
\hline \multicolumn{4}{|c|}{ Effect of incremental sample introduction } \\
\hline Rotated while pouring & $\mathrm{A}$ & 2 & 5.2 \\
\hline $\begin{array}{l}\text { Poured from one } \\
\text { location }\end{array}$ & A & 6 & 4.4 \\
\hline
\end{tabular}

cision of the laboratory measurements for mass, volume, and solids concentration is more than an order of magnitude smaller compared to the precision of tests with the cone splitter. This suggests the precision reported for the cone splitter is inherent in the cone splitter and not in the laboratory measurements.

Based on Levene's tests, there were no statistically significant differences between the precision of the cone splitters as a function of water volume or the manner in which the water was introduced. A statistical procedure-Levene's test-was used to show that the precision of the splitters was not affected by water volume or by the manner in which water was introduced. Levene's test compares the variance of sample sets which may have different means and can be used with data that may not be normally distributed (Encyclopedia of Statistical Sciences, 1983). Combining outlet ports slightly improved the precision. There also were no differences between variances of the two cone splitters at a volume of $0.6 \mathrm{~L}$. The data in table 2 indicate that the all-Teflon cone splitter splits a volume of water into equal aliquots with less than 5 percent relative standard deviation. For actual field use, this implies that sequentially introduced aliquots with different concentrations of dissolved constitu- 
ents will be effectively combined into equivalent replicate subsamples.

\section{Solids-Splitting Tests}

Tests of the precision of the cone splitter for solids with particle diameters greater than $38 \mu \mathrm{m}$ were made with cone splitter "A" (table 1). For solids with particle diameters less than $38 \mu \mathrm{m}$, tests were made with cone splitter "B" (table 1). One comparison of the two cone splitters was made (200 $\mathrm{mg} / \mathrm{L}$ for solids with particle diameters between 38 and $62 \mu \mathrm{m})$.

Results for one particle-size fraction (21-38 $\mu \mathrm{m})$ are illustrated in figure 2 . Water volume, solids mass, and solids concentration are plotted as bars for each of the 10 outlet ports, and mean water volume, mean solids mass, and mean solids concentration are plotted as horizontal lines. The percentage of deviation from the mean for the solids concentration from each port is printed above the respective bar.

A summary of the tests for nine particle-size ranges at two concentrations each is presented in figure 3. Two important observations can be made from this graph. First, the all-Teflon cone splitter is able to split particles that are smaller than coarse sand with a \%RSD of less than 7 percent. For larger particles, the cone splitter is much less precise. The second observation is that there is no systematic difference in the precision of the cone splitter as a function of solids concentration, at least for particle diameters of less than $500 \mu \mathrm{m}$. For larger particles, the cone splitter seems to be less precise for the lower solids concentration.

The precision in the splitting ability of the two different cone splitters can be compared from two tests with 38 to $62 \mu \mathrm{m}$ particles at $200 \mathrm{mg} / \mathrm{L}$. The range of percent deviation from the mean is -6.8 to 11.7 percent for " $\mathrm{A}$ " and -9.5 to 10.4 percent for "B." The \%RSDs were 5.2 and 7.7 percent, respectively. There seemed to be little systematic difference in the precision of the two cone splitters. The \%RSD in figure 3 for the three smallest particle sizes (data from splitter "B") are in the same range as the next four larger sizes (data from splitter "A"). This also suggests that the two splitters yield similar results.
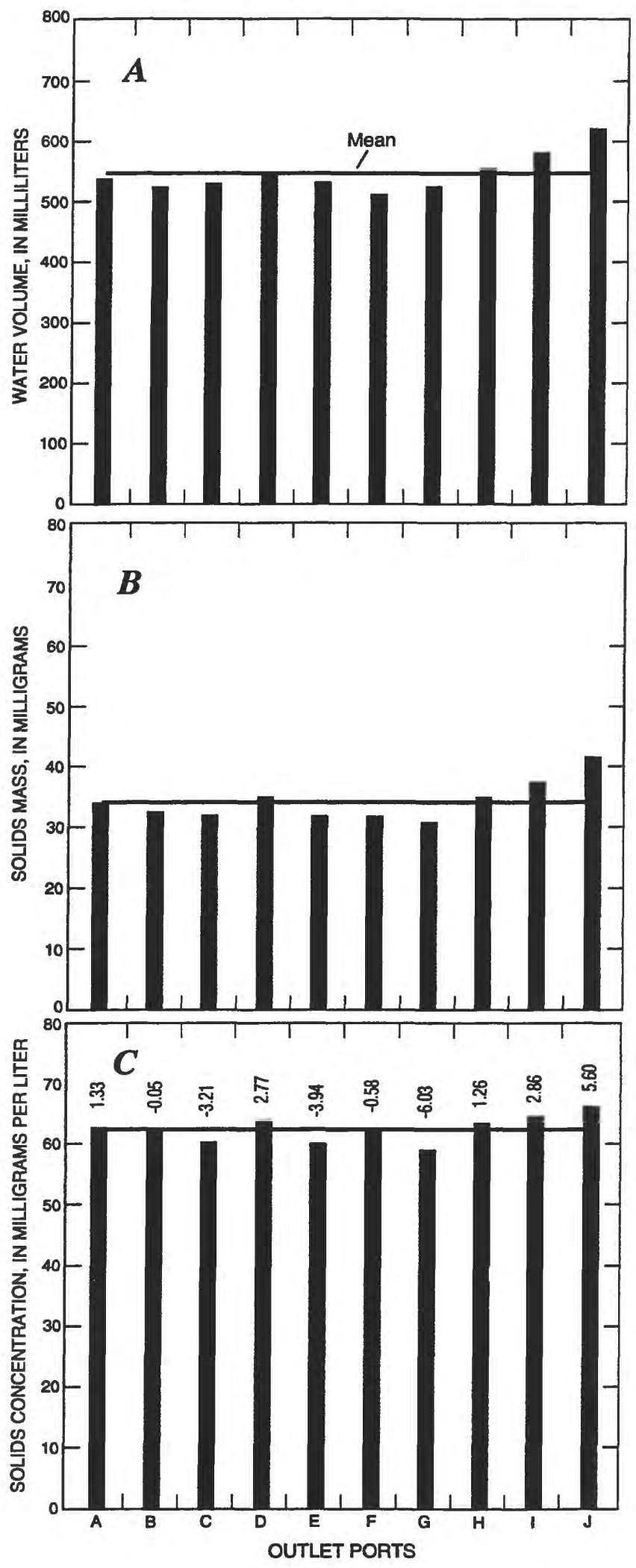

Figure 2. Example results from a split of solids and water. Solids diameter, 21-38 micrometers; solids concentration, 50 milligrams per liter. The percentage of deviation from the mean solids concentration is given above the solids concentration bar. 


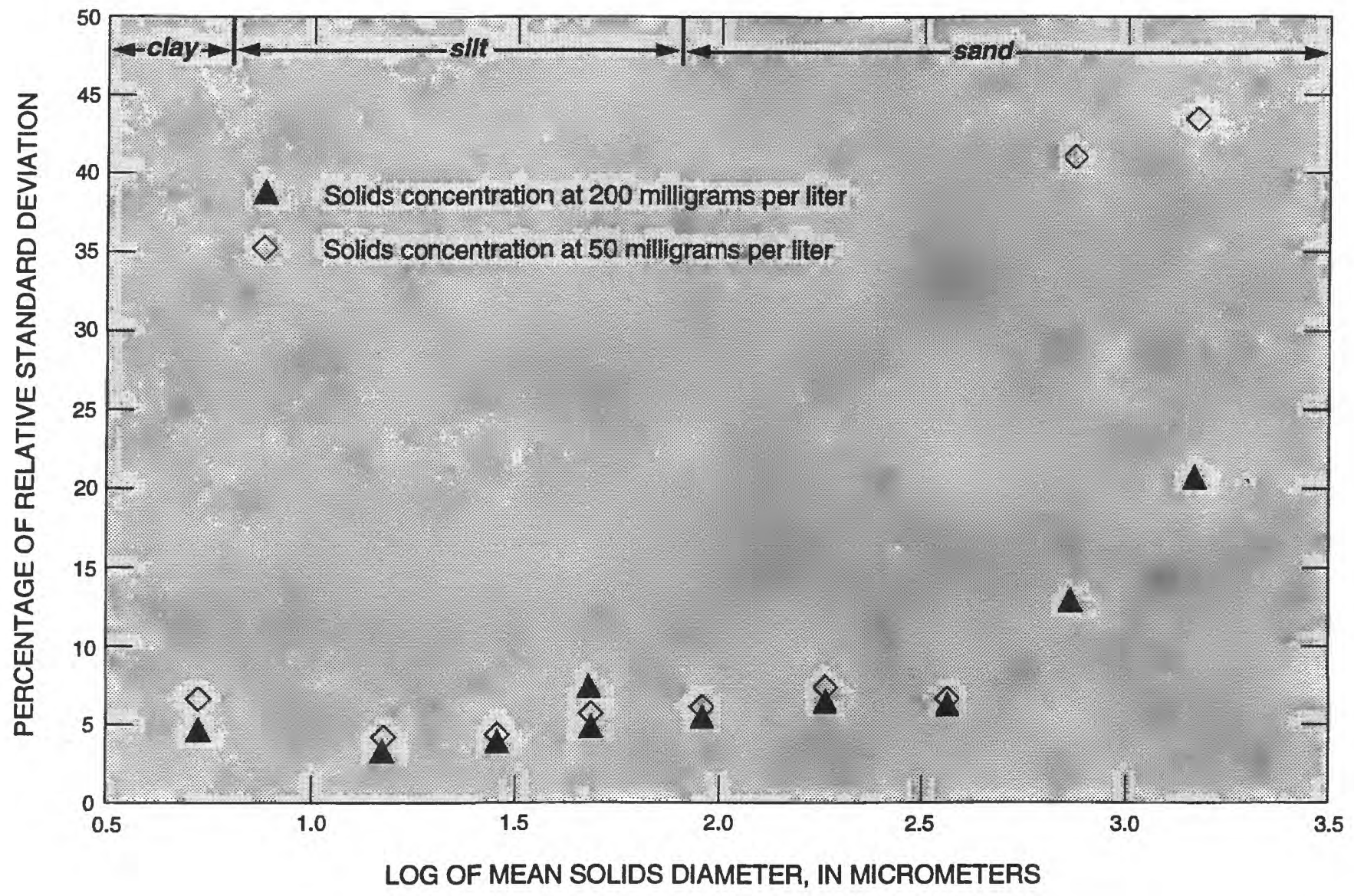

Figure 3. Effect of solids diameter and concentration on the percentage of relative standard deviation of the solids splitting. Cone splitter "A" was used for the six largest particle diameter ranges; cone splitter "B" was used for the four smallest particle ranges. Both splitters were tested for solids in the 1.5 to $2.0 \mathrm{log}$ of mean solids diameter range, at 200 milligrams per liter (62-38 micrometer diameter range, table 1).

\section{CONCLUSIONS}

The all-Teflon cone splitter is able to split a water sample with less than 5 percent relative standard deviation. The ability of the all-Teflon cone splitter to split solids is a function of particle diameter. Particles smaller than coarse sand are split with less than 7 percent relative standard deviation; larger particles have a greater error but improve with increased concentration. Potentially, the allTeflon cone splitter can split a water sample for subsequent analysis of semi-volatile organic chemi- cals and trace elements without contamination. If the precision of the all-Teflon cone splitter is sufficient for the purposes of a given study, then it would be useful in obtaining water sample splits for analysis of suspended solids, semi-volatile organic chemicals, and other water-quality constituents.

\section{REFERENCE CITED}

Encyclopedia of Statistical Sciences, 1983: New York, John Wiley, V. 4, p. 608-610. 